\title{
Prevention of esophageal stenosis after large endoscopic submucosal dissection: is there a better way to use steroids?
}

Authors

Institutions
Mathieu Pioche ${ }^{1,2}$, Jérôme Rivory ${ }^{1}$

'Endoscopy and Gastroenterology Division, Edouard Herriot Hospital, Lyon, France

2 INSERM, U1032 LabTau, Lyon, France submitted

13. December 2014 accepted after revision

7. January 2015

\section{Bibliography}

DOI http://dx.doi.org/

10.1055/s-0034-1391414

Published online: 27.2.2015

Endoscopy International Open

2015; 3: E118-E119

(c) Georg Thieme Verlag KG

Stuttgart · New York

E-ISSN 2196-9736

\section{Corresponding author}

Mathieu Pioche, MD

Gastroenterology and

Endoscopy Division

Pavillon L, Edouard Herriot

Hospital

5, Place d'Arsonval

69437 Lyon Cédex 03

France

Fax: +33-4-72-11-01-47

Mathieu.pioche@chu-lyon.fr
When an endoscopic resection involves more than $50 \%$ to $75 \%$ of the esophageal circumference, the risk of stenosis drastically increases to between $68 \%$ and $90 \%$, respectively [ $1-3$ ]. In the past, a wait-and-see attitude was prevalent, and treatment was initiated only for patients with symptomatic stenosis. Treatment was based on endoscopic balloon dilation (EBD) conducted in several sessions, with a significant effect on the patient's quality of life [3]. Gradually, it became clear that a prophylactic strategy was essential to reduce the number of unfavorable issues.

In parallel, either alone [4] or combined with EBD [5], steroids proved beneficial for the treatment of benign stenosis. Based on these results, it was naturally proposed that they be included in prophylactic strategies. As has been shown in many indications, these drugs are very effective for reducing inflammation and scarring, but they are associated with many severe adverse effects, such as metabolic disorders, infections, and osteoporosis, depending on the dose. The benefitto-risk ratio is a key point in any preventive strategy for asymptomatic patients. Thus, two different approaches progressively emerged: local injections in the ulcer bed and oral intake of steroids.

In the local approach, steroids are injected into the submucosa and edges of the resection bed. By reducing the synthesis of collagen and enhancing its breakdown, these local treatments have proved effective in reducing the incidence of stenosis [6] in corrosive esophagitis. For endoscopic resections involving up to $50 \%$ of the circumference, three sessions of local injections (at 3, 7, and 10 days) of low doses of triamcinolone (between 18 and $62 \mathrm{mg}$ ) significantly reduced the incidence of stenosis from $75 \%$ to $19 \%$ [7]. Furthermore, the mean number of balloon dilations for a patient with symptoms of stenosis was reduced from 6.6 to 1.7 procedures. In this experience, no side effects were reported, but in some studies in- jecting different drugs, severe issues were rarely encountered, including fatal mediastinitis, perforations, and pleural effusion $[6,8]$. Thus, importance of reducing the dose and the number of procedures rapidly became apparent, and a single session of injection was tested with successful outcomes [9].

Some patients with stenosis resistant to local injections underwent systemic steroid therapy with good outcomes, illustrating the superior power of repeated and high-dose systemic administration $[10,11]$. Oral steroids appeared to be a compromise between local and systemic injections. Given to patients undergoing prophylactic balloon dilations for resections involving more than $50 \%$ of the circumference, oral steroids reduced the incidence of stenosis from $32 \%$ to $5 \%$, with a decrease in the mean number of dilations required from 15.6 to 1.7 procedures [5]. Systematic balloon dilation entails its own morbidity inasmuch as the mucosal defect is recent, with a relatively high risk of perforation. Furthermore, steroid administration for 8 weeks, leading to a high cumulative dose of more than $1000 \mathrm{mg}$, is associated with well-known adverse effects on the bones and adrenal glands and the development of metabolic disorders and infections.

At present, steroid-free alternative strategies are being evaluated and offer different solutions. Among them, local grafts of tissue-engineered cell sheets [12], amniotic membrane [13], or gastric mucosa [14] seem promising for reducing the number of cases of stenosis in small, preliminary preclinical reports. However, the real effectiveness and safety of these grafts are not yet known, and several large studies should be conducted before we can think of discontinuing steroid use. Steroids are the only effective option currently available for preventing stenosis after a large ESD in the esophagus, but the optimization of treatment with lower doses that are effective but safer appears necessary. 
In the present issue of Endoscopy International Open, Kataoka et al. report testing a short and low dose steroid treatment to prevent stenosis after esophageal ESD involving up to $50 \%$ of the circumference. Although the two study groups were not treated during the same period, the same ESD technique was used. Furthermore, the investigators did not use systematic EBD after the ESD procedure, allowing the effects of steroids alone to be evaluated. With an average cumulative dose of $420 \mathrm{mg}$ of prednisolone within 3 weeks, the incidence of stenosis was $17.6 \%$, whereas it was $68 \%$ without prevention. In addition, the authors considered not only symptomatic stenosis but also the inability to pass a 9.2-mm gastroscope at 8 weeks after ESD. For the patients in whom stenosis developed, the mean number of EBDs required was 4.6 in the steroid group compared with 8.1 in the control group. In other words, low dose oral steroids reduced the number of cases of stenosis and its severity when it developed. No steroid-related adverse events occurred in the relatively short 12-month follow-up period. Although this work is not comparative and randomized, it introduces steroid dose reduction in the prevention of esophageal stenosis.

In regard to steroid-related adverse events, the risk of bone fractures appears at doses of up to $7.5 \mathrm{mg}$ per day during 3 months in the guidelines of the European League Against Rheumatism [15]. Such treatment represents a cumulative dose of $675 \mathrm{mg}$, and the change from $1000 \mathrm{mg}$ for 8 weeks in the current strategies to 420 $\mathrm{mg}$ for 3 weeks in this study is highly beneficial in preventing the induction of osteoporosis. We need comparative data on the effectiveness of the low dose and the high dose to support the reduced-dose strategy. As we await these evaluations, we have to remember to implement all the prophylactic measures needed for patients on steroid therapies, including calcium and vitamin $\mathrm{D}_{3}$ supplementation, bisphosphonate treatment (cumulative dose of $>675 \mathrm{mg}$ ) [15], physical activity, control of body weight, and a low fat and low salt diet.

To summarize, post-ESD esophageal stenosis is a frequent issue, and prophylactic strategies in which steroids are used are effective and can be justified. The choice of steroid strategy - local injections or oral intake - is not clear, and comparative studies are needed. The present paper introduces a new concept for endoscopists - low dose oral intake - and demonstrates its effectiveness. This dose reduction is known to decrease the number of adverse events, in particular those involving the bones, and must be spread out. In the meantime, without comparative work, we must remember to implement all the prophylactic measures needed for patients taking steroids to minimize their negative effects.

\section{Competing interests: None.}

\section{Acknowledgement}

\section{$\nabla$}

We thank Dr. Clémentine Gandilhon for her advice during the preparation of this editorial.

\section{References}

1 Ono S, Fujishiro M, Niimi $K$ et al. Predictors of postoperative stricture after esophageal endoscopic submucosal dissection for superficial squamous cell neoplasms. Endoscopy 2009; 41: 661-665

2 Mizuta H, Nishimori I, Kuratani Yet al. Predictive factors for esophageal stenosis after endoscopic submucosal dissection for superficial esophageal cancer. Dis Esophagus 2009; 22: 626-631

3 Hanaoka N, Ishihara $R$, Takeuchi $Y$ et al. Intralesional steroid injection to prevent stricture after endoscopic submucosal dissection for esophageal cancer: a controlled prospective study. Endoscopy 2012; 44: $1007-1011$

4 Zein NN, Greseth JM, Perrault J. Endoscopic intralesional steroid injections in the management of refractory esophageal strictures. Gastrointest Endosc 1995; 41: 596 - 598

5 Yamaguchi N, Isomoto H, Nakayama T et al. Usefulness of oral prednisolone in the treatment of esophageal stricture after endoscopic submucosal dissection for superficial esophageal squamous cell carcinoma. Gastrointest Endosc 2011; 73: 1115-1121

6 Kochhar R, Ray JD, Sriram PV et al. Intralesional steroids augment the effects of endoscopic dilation in corrosive esophageal strictures. Gastrointest Endosc 1999; 49: 509-513

7 Hashimoto S, Kobayashi M, Takeuchi M et al. The efficacy of endoscopic triamcinolone injection for the prevention of esophageal stricture after endoscopic submucosal dissection. Gastrointest Endosc 2011; 74: $1389-1393$

8 Marjoux S, Pioche M, Benet $T$ et al. Fatal mediastinitis following botulinum toxin injection for esophageal spasm. Endoscopy 2013; 45: E405-E406

9 Hanaoka N, Ishihara R, Takeuchi Y et al. Intralesional steroid injection to prevent stricture after endoscopic submucosal dissection for esophageal cancer: a controlled prospective study. Endoscopy 2012; 44: $1007-1011$

10 Morikawa N, Honna T, Kuroda T et al. High dose intravenous methylprednisolone resolves esophageal stricture resistant to balloon dilatation with intralesional injection of dexamethasone. Pediatr Surg Int 2008; 24: 1161 - 1164

11 Hishiki T, Kouchi K, Saito $T$ et al. Successful treatment of severe refractory anastomotic stricture in an infant after esophageal atresia repair by endoscopic balloon dilation combined with systemic administration of dexamethasone. Pediatr Surg Int 2009; 25: 531 - 533

12 Ohki T, Yamato M, Ota $M$ et al. Prevention of esophageal stricture after endoscopic submucosal dissection using tissue-engineered cell sheets. Gastroenterology 2012; 143: 582-588.e1-2

13 Barret M, Pratico CA, Camus $M$ et al. Amniotic membrane grafts for the prevention of esophageal stricture after circumferential endoscopic submucosal dissection. PloS One 2014; 9: e100236

14 Hochberger J, Koehler P, Wedi E et al. Transplantation of mucosa from stomach to esophagus to prevent stricture after circumferential endoscopic submucosal dissection of early squamous cell. Gastroenterology 2014; 146: 906 - 909

15 Hoes JN, Jacobs JWG, Boers $M$ et al. EULAR evidence-based recommendations on the management of systemic glucocorticoid therapy in rheumatic diseases. Ann Rheum Dis 2007; 66: 1560-1567 